\title{
Occurrence of entomopathogenic fungi in Atlantic forest soils
}

\author{
Margy Alejandra Esparza Mora ${ }^{1 *}$, Janaina Ribeiro Costa Rouws ${ }^{2 \dagger}$ and Marcelo Elias Fraga ${ }^{3 \dagger}$ \\ *Correspondence: aleesparza18@hotmail.com

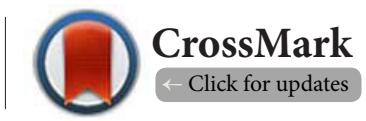 \\ 'These authors contributed equally to this work. \\ ${ }^{1}$ Institute of Biological Science and Health, Federal Rural University of Rio de Janeiro, BR 465 Km 07, ZIP. 23890-000, Seropedica, RJ, Brazil. \\ ${ }^{2}$ Embrapa Agrobiology, BR 465, Km 07, ZIP. 23890-000, Seropedica, RJ, Brazil. \\ ${ }^{3}$ Mycology Laboratory, Veterinary Institute, Federal Rural University of Rio Janeiro, BR 465 Km 07, ZIP. 23890-000, Seropedica, RJ, Brazil.
}

\begin{abstract}
Knowledge of the composition and distribution of native entomopathogenic fungal species are essential to evaluate the potential of biological control in a given ecosystem. In this study, 10 soil samples were collected in two seasons (dry and rainy) in the Curió Municipal Natural Park in Paracambi and the presence of entomopathogenic fungi species was evaluated. The isolation was carried out using two methods: the bait method with Galleria mellonella and Tenebrio molitor larvae and the selective media Agar Potato Dextrose method supplemented with insect integument (PDA+IT) and Martin medium. A total of 216 isolates of entomopathogenic fungi were isolated. The bait method with larvae collected $88.0 \%$, while the PDA+IT media and Martin method caught $12.0 \%$. The most predominant species was Beauveria bassiana isolated with G. mellonella in the dry (36.0\%) and in the rainy (36.0\%) season. Metarhizium anisopliae was isolated, mostly in T. molitor in the dry (33.3\%) and in the rainy (32.0\%) season. Beauveria bassiana was less prevalent in the Martin medium, occurring $13.3 \%$ in the dry and $33.3 \%$ in the rainy season. The occurrence of B. bassiana using the PDA+IT medium was $33.3 \%$ in the dry and $20.0 \%$ in the rainy season. The higher incidence of $M$. anisopliae (26.7\%) was in the rainy season with the PDA+IT medium. The higher incidence of entomopathogenic fungi was observed using the bait method with high frequencies of B. bassiana and M. anisopliae. The bait method with G. mellonella and T. molitor is a sensitive method for the isolation of entomopathogenic fungi in soil.
\end{abstract}

Keywords: Beauveria bassiana, Metarhizium anisopliae, biological control, natural enemies, biodiversity

\section{Introduction}

The soil environment is an important reservoir for a wide variety of entomopathogenic fungi, which can significantly contribute to the control of insect populations, including agricultural and forest pests [19]. The occurrence and distribution of entomopathogenic fungi in soils have been widely investigated $[27,30]$. Many species belonging to Hypocreales (Ascomycota) live in the soil for a significant part of their life cycle. Of these, Beauveria sp., Metarhizium anisopliae (Metchnikoff) Sorokin and Isaria spp. (formally known as Paecilomyces) are especially common and have the greatest potential for use in biological control [51].

Two methods are generally used to detect entomopathogenic fungi in soil. The method using Galleria mellonella (Lepidoptera),
Tenebrio molitor (Coleoptera) or other insect baits is relatively simple and sensitive $[\mathbf{3 8 , 4 3 , 4 4 , 4 9 ]}$. The principal advantage of this method is the selective isolation of entomopathogenic fungi that are biologically active [22]. The plating method using various selective media $[10,25,37]$ is particularly advantageous when quantification is required or when the material to be analyzed is not soil.

Calculation of diversity in fungal estimated world was 1.5-5.1 million species [14], of which only 100,000 have been described [47]. Of these, approximately 750-1,000 entomopathogenic fungi have been classified into more than 100 genera [39]. The entomopathogenic fungi constitute the greatest number of taxa of insect pathogens [17]. About 171 commercial preparations based on entomopathogenic fungi were in use 
Esparza Mora et al. Microbiology Discovery 2016,

or in development in 2007, the majority of them based on Beauveria bassiana, B. Brongniartii, Metarhizium anisoplae and Isaria fumorosea [9].

This study aimed to compare two methods for the isolation of entomopathogenic fungi, the bait method versus direct isolation method, and analysis of their occurrence in the Atlantic Rain Forest soil.

\section{Materials and methods \\ Soil sample}

The study area is located inside the Curió Municipal Natural Park in Paracambi in the state of Rio de Janeiro. The park is in the Atlantic Forest biome, situated approximately between the geographical coordinates, latitude: $22^{\circ} 26^{\prime} 34^{\prime \prime} \mathrm{S}$ and longitude: $043^{\circ} 27^{\prime} 33^{\prime \prime} \mathrm{W}$ with an average altitude of $690 \mathrm{~m}$, and an area of approximately 900 ha.

Samples were collected at two different seasons, the first collection was in the dry seasons, at the end August 2014 (C1), and the second was in the rainy period at the beginning of March 2015 (C2). Five sampling points $10 \mathrm{~m}$ apart were selected. The sampling protocol was: 1-The vegetation on the surface of soil and the forest floor litter were removed; 2 - at each point 10 simple random sub-samples were taken in the rhizosphere, at a depth of $5-20 \mathrm{~cm}$ and $1 \mathrm{~m}$ between each sub-sample with a volume of approximately $250 \mathrm{~g}$. These 10 sub-samples were mixed together to form one $2.5 \mathrm{~kg}$ composite sample; 3 - These composite samples were placed in sterile plastic bags and stored in a cold chamber at $4^{\circ} \mathrm{C}$ until processing and analysis.

Physical and chemical characterization of the soil samples was conducted by the Soil Fertility Laboratory of the Rural Federal University of Rio de Janeiro. The Soil fertility was evaluated using the following parameters: $\mathrm{pH}$ in water (pot method) [31], aluminum (Al) content (interchangeable), hydrogen plus aluminum $(\mathrm{H}+\mathrm{Al})$, phosphorus $(\mathrm{P})$, potassium $(\mathrm{K})$, calcium (Ca), organic carbon (orgC) and magnesium (Mg) (exchangeable) to depths of $5-20 \mathrm{~cm}$ soil. The soil analytical methods were adapted from Embrapa [7]; whereas for classification, the Brazilian System of Soil Classification method was used.

\section{Isolation of entomopathogenic fungi}

The following methods for the isolation of entomopathogenic fungi were used: 1- "bait method" (BM) with Galleria mellonella (Lepidoptera: Pyralidae) and Tenebrio molitor (Coleoptera: Tenebrionidae) applying the methodology described by 49 and 28, 2- "plating method" in selective medium (SM) Potato Dextrose Agar (PDA) (Merck KGaA, Germany) supplemented with insect integument (T. Molitor) (PDA+IT) and Martin medium. Larvae of the fourth stage of G. mellonella and T. molitor supplied by the Biology Institute in Campinas -SP were used. The first isolation method used G. mellonella larvae, which were immersed in water at $56^{\circ} \mathrm{C}$ for $15 \mathrm{~s}$ to minimize their ability to produce silk in the soil before baiting [48]. Five larvae of each species of insect were placed in a plastic container $(2 \mathrm{~L})$ containing $250 \mathrm{~g}$ soil, moistened and maintained at $25 \pm 1^{\circ} \mathrm{C}$, each sample had three replicates. Each container was inverted during the first 3 days and subsequently every 2 days. After the 5 days the containers were evaluated daily for dead larvae. The dead larvae were removed and sterilized with $0.5 \%$ sodium hypochlorite for $1 \mathrm{~min}$ [27], and placed in a humid chamberfor 5 days. After sporulation, the larvae were placed on PDA with chloramphenicol.

In the second isolation method, the selective media (Martin and PDA+IT) method, $5 \mathrm{~g}$ of soil was suspended in $45 \mathrm{ml}$ of peptone water (Merck KGaA, Germany) with $0.1 \mathrm{ml}$ 1\% Tween 80 (Croda, Singapore) and stirred (150 rpm) in a shaker for 30 $\mathrm{min}$. An aliquot of $1 \mathrm{ml}$ of this homogeneous suspension was removed and placed in a tube with $9 \mathrm{ml}$ of peptone water, and so forth, were prepared decimal dilutions to $10^{-4} .100 \mathrm{\mu L}$ were inoculated from dilutions $10^{-1}, 10^{-2}$ and $10^{-3}$ on MS plates and incubated at $25 \pm 1^{\circ} \mathrm{C}$. Each dilution had three repetitions and each sample had three dilutions plated [12]. The colony forming units (CFUs) per gram of soil were counted on the 7th day after the inoculation.

The fungal species obtained by both methods were identified based on the macroscopic and microscopic characteristics using identification keys [16,35].

\section{Statistical analysis}

The occurrence of fungi as indicated by the BM was represented as logical data (either present or absent). Quantitative data obtained by the SM plating method were expressed as CFUs per gram of soil and by logical indication.

The design for the experiment in selective medium was completely random with 15 repetitions and treatments consisting of the factorial $2 \times 2$, two culture media (Martin and $\mathrm{BDA}+\mathrm{IT}$ ) and the two evaluation seasons (dry and rainy). The means of the logCFUs data were evaluated by the F-test of the analysis of variance and the frequency of occurrence of the entomopathogenic fungi were compared using the nonparametric Wilcoxon test, at $5 \%$ probability.

The percentage of larvae killed by entomopathogenic fungi, live larvae and the frequency of occurrence of the entomopathogenic fungi as shown by the bait method were evaluated according to a completely random design with 15 repetitions (larvae) in a factorial scheme $2 \times 2$, totaling 4 treatments. The treatments consisted of combinations among the levels of factors, types of bait (G. mellonella and T. molitor) and evaluation seasons (dry and rainy). The comparison of means between the levels of factors was performed using the nonparametric Wilcoxon test at $5 \%$ probability.

\section{Results}

A total of 216 isolates of entomopathogenic fungi were isolated from the Atlantic Rain Forest biome. The bait method with larvae collected $87.96 \%$ and the method with selective media collected $12.03 \%$. 
When the selective media (Martin and PDA+IT) method was used significant differences were obtained between seasons and between the media culture used (Figure 1). In the selective Martin medium ( $p=0.0024)$ more CFUs were observed in the rainy season (3.81 logCFU g ${ }^{-1}$ soil) compared to the dry season, which showed a lower number of CFU (3.77 logCFU g ${ }^{-1}$ soil). There were also significant statistical differences $(p=0.0000)$ between the seasons for the PDA medium supplemented with T. molitor integument, with rainy and dry seasons presenting 3.67 and $3.60 \mathrm{logCFU} \mathrm{g}^{-1}$ soil, respectively. Among the media, Martin showed a significantly higher $(p=0.0000)$ average of CFUs than the PDA supplemented with integument of T. molitor both in the rainy (3.81 and $3.67 \log C F U ~ g^{-1}$ soil, respectively) and the dry seasons (3.77 and $3.70 \log \mathrm{CFU} \mathrm{g}^{-1}$ soil, respectively). The isolation using selective media provided a lower overall detection rate $(12.03 \%)$, and the isolates were typically found in larger quantities in the rainy season (Table 1). Beauveria bassiana was less prevalent in the Martin medium, where there was an occurrence of $13.3 \%$ in the dry season and $33.3 \%$ in the rainy season. Paecilomyces lilacinus was observed on the plates

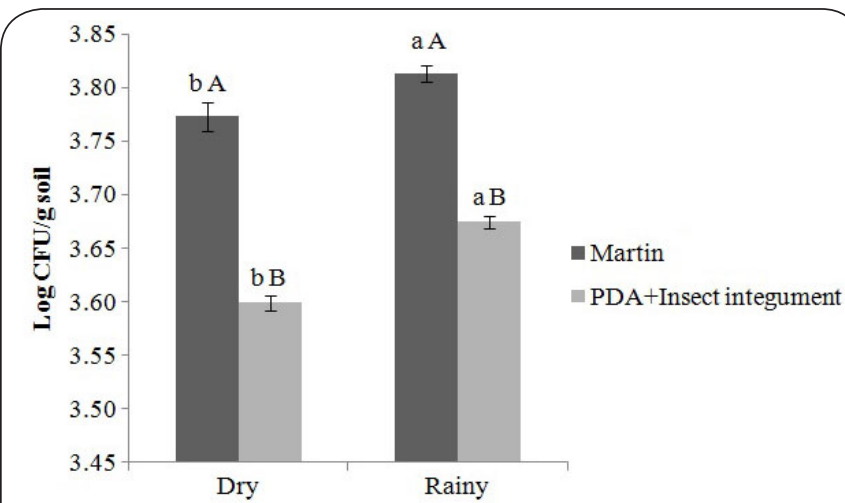

Figure 1. Mean values \pm standard errors of colony forming units (Log CFU/g of soil) of fungi in selective media Martin and PDA+ insect integument in the dry and rainy seasons. Bars indicated with different letters, lowercase between seasons and uppercase between culture media, differ by F-test at $5 \%$ probability.

Table 1. Occurrence of entomopathogenic fungi (n) in 15 soil samples collected in the Curio Municipal Natural Park using the isolation method with culture medium Martin and PDA+IT in the dry and rainy seasons.

\begin{tabular}{l|lllllllll}
\hline \multirow{2}{*}{$\begin{array}{l}\text { Fungal } \\
\text { Species }\end{array}$} & \multicolumn{4}{|c|}{ Dry } & \multicolumn{5}{c}{ Rainy } \\
\cline { 2 - 9 } & Martin & PDA+ IT & Martin & PDA+ IT \\
\cline { 2 - 9 } & n & \% & n & \% & n & \% & n & \% \\
\hline $\mathrm{Bb}$ & 2.0 & 13.3 & 5.0 & 33.3 & 5.0 & 33.3 & 3.0 & 20.0 \\
$\mathrm{Ma}$ & 0.0 & 0.0 & 2.0 & 13.3 & 0.0 & 0.0 & 4.0 & 26.7 \\
$\mathrm{Pl}$ & 0.0 & 0.0 & 2.0 & 13.3 & 1.0 & 6.7 & 5.0 & 33.3 \\
\hline \multicolumn{6}{c}{ Combinations } \\
\hline $\mathrm{Bb}+\mathrm{Ma}$ & 0.0 & 0.0 & 1.0 & 6.7 & 0.0 & 0.0 & 4.0 & 26.7 \\
\hline
\end{tabular}

Beauveria bassiana (Bb), Metarhizium anisopliae (Ma) and Paecilomyces lilacinum (Pl). occurring in $6.7 \%$ during the rainy season when the Martin medium was used; for PDA+IT, its occurrence was of $33.3 \%$ in the rainy season and $13.3 \%$ in the dry season. However, this specie was not included in further analysis because it is not considered pathogenic to insects. The frequency of occurrence of $B$. bassiana in the dry season (33.3\%) was higher than in the rainy season (20.0\%) using the PDA medium+IT. The highest incidence of $M$. anisopliae (26.7\%) was obtained in the rainy season using the PDA medium+IT. No growth was observed in the Martin medium for M. anisopliae. Combinations of $B$. bassiana and $M$. anisopliae also had a greater incidence in the rainy season $(26.7 \%)$ using PDA medium+IT.

The occurrence of entomopathogenic fungi using the isolation method with T. molitor larvae as bait was $61.33 \%$ in the dry season and $64 \%$ in the rainy season. With G. mellonella larvae the occurrence of entomopathogenic fungi was $60 \%$ and $68 \%$ in the dry and rainy seasons, respectively. However, there was no statistical difference between the dry and rainy seasons when used T. molitor ( $p=0.8127$ ) and G. mellonella larvae $(p=0.4781)$ (Figure 2).

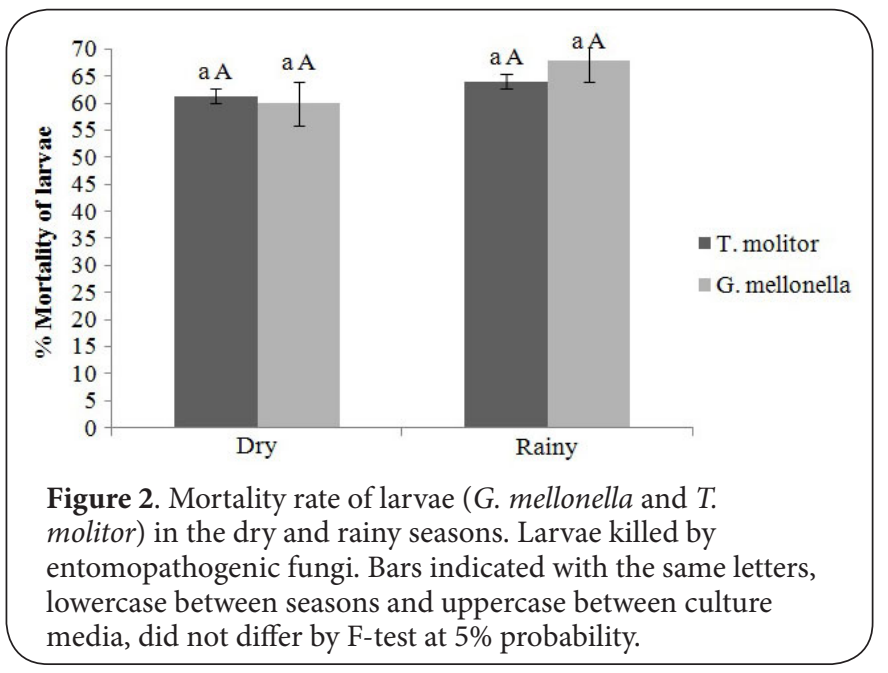

Entomopathogenic fungi were found in all samples. The occurrence of isolated species differed considerably depending on the species of insects used as bait (Table 2). The most predominant specie was Beauveria bassiana, isolated with G. mellonella in the dry and rainy seasons $36.0 \%$ and $36.0 \%$ respectively). Beauveria bassiana occurred in T. molitor larvae in the dry season (25.33\%) and in the rainy season (24.0\%). More Metarhizium anisopliae were isolated in T. molitor larvae in the dry (33.3\%) and rainy (32.0\%) seasons than B. bassiana. In G. mellonella larvae $M$. anisopliae occurred in $18.7 \%$ of the samples in both periods. A co-infection of larvae caused by two or more entomopathogens was observed in a total of 168 isolates, 91 belong to the species B. bassiana and 77 to the species M. anisopliae.

Table 3 shows the amount of nutrients: sodium ( $\mathrm{Na}$ ), calcium $(\mathrm{Ca})$, magnesium $(\mathrm{Mg})$, Hydrogen more aluminum $(\mathrm{H}+\mathrm{Al})$, alu- 
Esparza Mora et al. Microbiology Discovery 2016,

Table 2. Occurrence of entomopathogenic fungi (n) in 10 soil samples collected in the Curio Municipal Natural Park using the isolation method with larvae (T. molitor and G. mellonella), in the dry and rainy seasons.

\begin{tabular}{l|llllllll}
\hline \multirow{2}{*}{$\begin{array}{l}\text { Fungal } \\
\text { species }\end{array}$} & \multicolumn{5}{|c|}{ Dry } & \multicolumn{5}{c}{ Rainy } \\
\cline { 2 - 9 } & T. molitor & G. mellonella & T. molitor & G. mellonella \\
\cline { 2 - 9 } & n & $\%$ & n & $\%$ & n & $\%$ & N & $\%$ \\
\hline $\mathrm{Bb}$ & 19.0 & 25.3 & 27.0 & 36.0 & 18.0 & 24.0 & 27.0 & 36.0 \\
$\mathrm{Ma}$ & 25.0 & 33.3 & 14.0 & 18.6 & 24.0 & 32.0 & 14.0 & 18.6 \\
\hline \multicolumn{8}{c}{ Combinations } \\
\hline $\mathrm{Ma}+\mathrm{F}$ & 1.0 & 1.3 & 0.0 & 0.0 & 2.0 & 2.6 & 1.0 & 1.3 \\
$\mathrm{Bb}+\mathrm{F}$ & 0.0 & 0.0 & 1.0 & 1.3 & 0.0 & 0.0 & 4.0 & 26.7 \\
$\mathrm{~V}+\mathrm{F}$ & 0.0 & 0.0 & 2.0 & 2.6 & 0.0 & 0.0 & 0.0 & 0.0 \\
$\mathrm{Bb}+\mathrm{Ma}$ & 1.0 & 1.3 & 4.0 & 5.3 & 1.0 & 1.3 & 6.0 & 8.0 \\
$\mathrm{~N}+\mathrm{F}+\mathrm{T}$ & 0.0 & 0.0 & 0.0 & 0.0 & 0.0 & 0.0 & 3.0 & 4.0 \\
\hline
\end{tabular}

Beauveria bassiana (Bb), Metarhizium anisopliae (Ma), Fusarium sp. (F), Verticiullium sp. (V), Nomurea sp. (N) and Trichoderma sp. (T)

minum (Al), sulfur (S), organic carbon (orgC), phosphorus (P), potassium $(\mathrm{K})$ and $\mathrm{pH}$ values for the soil in the dry and rainy season samples, respectively. In general, the rainy season sample were higher for the $\mathrm{pH}$ values, $\mathrm{Na}, \mathrm{Ca}, \mathrm{Mg}, \mathrm{H}+\mathrm{Al}, \mathrm{Al}$ and $\mathrm{S}$.

\section{Discussion}

High densities of fungi were found in both selective media, although the Martin medium showed higher occurrence as the PDA, which was supplemented with integument of $T$. molitor during rainy season $\left(6.5 \times 10^{3} \mathrm{CFU} \mathrm{g}^{-1}\right.$ soil and $4.7 \times 10^{3}$ CFU g ${ }^{-1}$ soil, respectively). Scheepmaker and Butt (2010) found that densities of $M$. anisopliae and B. bassiana were highly variable, with concentrations of $10^{2}$ and $10^{3} \mathrm{CFU} \mathrm{g}^{-1}$ in soil [27]. Obtained an entomopathogenic fungus detection rate of $70 \%$ using selective media with Dodine and the most prevalent specie was M. anisopliae (37\%). The maximum spore densities were $5.4 \times 10^{3} \mathrm{CFU} \mathrm{g}^{-1}$ to B. bassiana, $8.13 \times 10^{2} \mathrm{CFU} \mathrm{g}^{-1}$ for M. anisopliae and $7.89 \times 10^{2} \mathrm{CFU} \mathrm{g}^{-1}$ for Isaria fumosorosea. [34] determined the natural occurrence of Metarhizium spp. in Brazilian Cerrado soils using selective media with Dodine, and 12 isolates were found.

The use of G. mellonella larvae produced the highest incidence of entomopathogenic fungi, verifying that the bait method with G. mellonella [49] is a very sensitive method for the detection of entomopathogenic fungi in soil samples [21]. Detailed surveys of the diversity of entomopathogenic fungi using bait insects in soil samples has been used by several authors $[15,28]$. In this work the entomopathogenic fungi species detected using bait larvae were: B. bassiana and M. anisopliae. These results supported those of [27] who noted that four species of entomopathogenic fungi were detected in soil samples in Slovakia using the bait method (BM) with G. mellonella: Beauveria bassiana (31\% of the samples isolated) Metarhizium anisopliae (8\%), Isaria farinosa (6\%) and Isaria fumosorosea (6\%). Only three species were detected by these authors with selective medium (cycloheximide and dodine): B. bassiana (36\% of the samples isolated), M. anisopliae (37\%), and $I$. fumosorosea (9\%).

According to [50], the most susceptible hosts for M. anisopliae are species of Coleoptera. For B. bassiana over 700 species of arthropod hosts are reported. However, the greatest abundance of Metarhizium species was presented on Coleoptera larvae, and the highest incidence of Beauveria was observed on Lepidoptera larvae.

The bait method with larvae of G. mellonella [49] is a sensitive method for the isolation of entomopathogenic fungi in soil [21]. Beauveria bassiana (Bals) Vuill as well as Metarhizium anisopliae (Metsch). Sorok and Metarhizium flavoviride Gams and Rozsypal are among the most commonly found entomopathogenic fungi in nature $[6,42]$ stated that $B$. bassiana and I. fumosorosea are more frequently isolated from a "natural" ecosystem than from cultivated soils, although $M$. anisopliae seems to be more common in cultivated soils. This observation indicates that $M$. anisopliae populations are more resistance to disturbances characteristic of farmed habitats [29]. In tropical forests, M. anisopliae can be readily isolated from soil samples using G. mellonella and T. molitor larvae [15]. All fungi found in this study have also been recorded

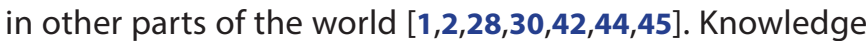
of the composition of the local entomopathogenic fungi species in the soil is needed to evaluate the potential of this group as a source of natural enemies for insect pest control in a specific agro-ecosystem.

The greater occurrence of $B$. bassiana in the soil is due to its preference in this natural environment. This preference has also been described by several authors including $[4,33,46]$. Metarhizium anisopliae is generally more resistant to agricultural disturbances and several studies have reported that its higher prevalence in cultivated areas is significant compared to natural habitats $[\mathbf{2}, \mathbf{2 8 , 3 3 , 4 2 ]}$. Reported a lower frequency of these species in cultivated soils in Denmark, but found that

Table 3. Physicochemical analysis of the soil carried out for both seasons (dry and rainy).

\begin{tabular}{lllllllllllll}
\hline $\begin{array}{l}\text { Chemical } \\
\text { elements }\end{array}$ & Texture & Na & Ca & Mg & $\begin{array}{l}\text { K } \\
\text { Cmolc/dm3 }\end{array}$ & H+Al & Al & S & pH & Org C\% & Pmg/L & K \\
\hline Dry season & Sandy loam & 0.04 & 3.46 & 1.54 & 0.13 & 2.22 & 0.55 & 5.16 & 5.3 & 2.016 & 17.4 & 50 \\
Rainy season & Sandy loam & 0.06 & 3.86 & 2.56 & 0.71 & 6.14 & 0.20 & 7.19 & 5.5 & 2.128 & 16.6 & 227 \\
\hline
\end{tabular}

Sodium (Na), Calcium (Ca), Magnesium (Mg), Potassium (K), Hydrogen (H), Aluminium (Al), Sulfur (S), Organic carbono (orgC) and phosphorus $(\mathrm{P})$. 
M. flavoviridae was significantly more common than usually reported. This study found a number of $M$. anisopliae species with a frequency of $45.83 \%$ and $B$. bassiana species occurring in $54.16 \%$ using the bait method.

Significant differences ( $p £ 0.01$ ) were found between the results obtained by the methods used. The method with selective medium was not able to detect high frequencies of M. anisopliae and B. bassiana; however, the method with larvae bait resulted in high detection rates of $B$. bassiana and Metarhizium anisopliae [46], detected entomopathogenic fungi in $38.6 \%$ of soil samples from Finland, while [33] found fungi in $71.7 \%$ of soil samples in Spain and [4] $15.8 \%$ of soil samples in the UK, all using the BM with G. mellonella [21], found entomopathogenic fungi in $96 \%$ of soil samples in Switzerland when using selective medium along with BM and G. mellonella. These authors also concluded that baiting with G. mellonella in soil samples tends to be more sensitive for the detection of entomopathogenic fungi than using the selective agar method [15]. Determined the diversity of entomopathogenic fungi in tropical forest soils in Panama using G. mellonella and T. molitor larvae and a selective medium with dodine, which resulted in 58 isolates of Metarhizium anisopliae with the bait method, and one strain of $B$. bassiana isolated with the selective medium method.

In Brazil the occurrence of Metarhizium spp. using Triatomainfestans nymphs (Hemiptera: Reduviidae) and selective medium modified with dodine was verified. A total of 107 (22\%) isolates of Metarhizium were obtained in Brazilian cerrado soils in the state of Goiás; 95 were obtained using the T. infestans nymphs and 12 were obtained in a selective medium $[32,34]$. Determined the abundance and diversity of entomopathogenic fungi in agricultural soils in Mexico, using G. mellonella larvae as bait. Only entomopathogenic fungi of the genus Beauveria sp. and Metarhizium sp. were recovered. Overall, a total of 121 isolates were recorded and 112 were of the genus Beauveria and 9 of the genre Metarhizium. In other studies $M$. anisopliae was isolated approximately four times more often by the selective medium than by the bait method with G. mellonella, although higher sensitivity of the bait method with G. mellonella has been reported by several other authors and differences have also been reported for $B$. bassiana $[3,18,23]$. Almost all methods used today show some selectivity to species. The bait method is used more often and can detect a relatively large number of species, but it only detects the pathogenic isolates of bait insects. Variations were detected when different species of bait insect are used $[5,22,46]$. Currently, the selective media normally used are only able to detect a few different entomopathogenic fungi reliably. Thus, more than one medium is needed to obtain a realistic view of the composition of species of entomopathogenic fungi in soils.

The occurrence of M. anisopliae and B. bassiana was not affected by the physical and chemical properties of the soil. The soil analyzed showed a sandy loamtexture and organic carbon content of $2.012 \%$ in the dry season and $2.118 \%$ in the rainy season. Several authors $[\mathbf{8 , 1 9 , 2 4 ]}$ have reported that the organic matter content and soil biological activity adversely affect the persistence of Beauveria spp. due to antagonistic effects caused by other soil micro-organisms. Secondly, [27] found a higher occurrence of $B$. bassiana and I. farinosa in soils with a high content of organic matter and minerals in soils of fine texture. Furthermore, M. anisopliae and I. fumosorosea are less common in such conditions [33], found $M$. anisopliae in coarse textured soils with high organic matter content and B. bassiana was found in soils with high clay content, high $\mathrm{pH}$ and higher organic matter content of less than 1-3\% (41.3\% occurrence) or $2-3 \%$ (25\% occurrence). The latter two important variables in the presence of Beauveria and Metarhizium genres [33]. Humidity is a factor that is related to soil texture, but [41] found that clay soils saturated with water appear to inhibit the infection of $B$. bassiana, while in sandy soils this inhibition does not occur [40]. Showed that the temperature and soil moisture are key factors for the formation of conidia in the soil. High humidity and high soil temperatures reduce the survival of conidia and the infectivity of Beauveria spp [28].

Fungi in general are more tolerant to the acidity than the alkalinity [11]. In this study the $\mathrm{pH}$ measured in the dry period and the rainy season was 5.3 and 5.5 respectively [27]. Found a significant correlation between the soil pH and the presence of fungi. M. anisopliae occurred more often in soils with an alkaline $\mathrm{pH}$ while $B$. bassiana and I. farinosa preferred an acidic environment. In Spain [33], found that B. bassiana had the highest occurrence (52.9\%) with $\mathrm{pH} \geq 8-8.5$ and $M$. anisopliae showed a $27.8 \%$ occurrence with $\mathrm{pH}<7$ and $38.9 \%$ with $\mathrm{pH} \geq 8-8.5$.

\section{Conclusion}

B. bassiana and M. anisopliae isolates were found in soils of the Atlantic Rain Forest biome in the state of Rio de Janeiro, and $B$. bassiana was the most abundant species. The higher incidences of entomopathogenic fungi were observed with the bait method -the higher incidence of the Metarhizium species using T. molitor larvae and Beauveria using G. mellonella larvae. These results represent an important contribution to the understanding of entomopathogenic fungi in the soil of the Atlantic Rain Forest biome in Rio de Janeiro and provide the basis for future research onthe subject.

\section{Competing interests}

The authors declare that they have no competing interests.

\section{Authors' contributions}

\begin{tabular}{|l|c|c|c|}
\hline Authors' contributions & MAE & JRC & MEF \\
\hline Research concept and design & -- & -- & -- \\
\hline Collection and/or assembly of data & $\checkmark$ & -- & $\checkmark$ \\
\hline Data analysis and interpretation & $\checkmark$ & -- & -- \\
\hline Writing the article & $\checkmark$ & $\checkmark$ & -- \\
\hline Critical revision of the article & $\checkmark$ & -- & $\checkmark$ \\
\hline Final approval of article & -- & -- & $\checkmark$ \\
\hline Statistical analysis & -- & $\checkmark$ & -- \\
\hline
\end{tabular}


Esparza Mora et al. Microbiology Discovery 2016,

\section{Acknowledgement}

The Biological Control Laboratory of the Biological Institute in Campinas, Sao Paulo, for providing the G. mellonella and T. molitor larvae. The Soil Fertility Laboratory of the Federal Rural University of Rio de Janeiro (UFRRJ) for carrying out the physical and chemical analysis of the soil.

\section{Publication history}

Editor: Saad J. Taj-Aldeen, Hamad Medical Corporation, Qatar. EIC: Jose Ruiz-Herrera, National Polytechnic Institute, Mexico. Received: 08-Jan-2016 Final Revised: 09-Feb-2016

Accepted: 23-Feb-2016 Published: 04-Mar-2016

\section{References}

1. Aung OM, Soytong $K$ and Hyde KD. Diversity of entomopathogenic fungi in rainforests of Chiang Mai Province, Thailand. Fungal Divers. 2008; 30:15-22. I Pdf

2. Bidochka MJ, Kasperski JE and Wild GAM. Occurrence of the entomopathogenic fungi Metarhizium anisopliae and Beauveria bassiana in soils from temperate and near-northern habitats. Can J Botany. 1998; 76:1198-1204. | Article

3. Bruck DJ. Natural occurrence of entomopathogens in Pacific Northwest nursery soils and their virulence to the black vine weevil, Otiorhynchus sulcatus (F.) (Coleoptera: Curculionidae). Environ Entomol. 2004; 33:1335-1343. | Article

4. Chandler D, Hay D and Reid AP. Sampling and occurrence of entomopathogenic fungi and nematodes in UK soils. App/ Soil Ecol. 1997; 5:133-141. | Article

5. Enkerli J, Moosbauer P, Widmer F, Dorn S and Keller S. Isolation of Beauveria brongniartii from soil: are the available isolation tools neutral?. IOBC/wprsBulletin. 2005; 28:25-29. | Article

6. Elosegui CO. Métodos artesanales de producción de bioplaguicidas a partir de hongos entomopatógenos antagonistas. La Habana-Cuba: Instituto de Investigaciones de Sanidad Vegetal (INISAV). 2006; 6-8. I Pdf

7. Embrapa. Manual de métodos de análise de solos. Serviço Nacional de Levantamento e Conservação do Solo. 2.ed., Embrapa, Rio de Janeiro. 1997.

8. Fargues $\mathrm{J}$ and Robert PH. Persistence of conidia of four entomopathogenic Hypomycetes in soil, Beauveria bassiana (Bals.) Vuill. Metarhizium anisopliae (Metsch.) Sor. Nomurea rileyi (F.) Samson and Paecilomyces fumosoroseus Wize, in controlled conditions. Agronomie. 1985; 5:73-80.

9. Faria MR and Wraight SP. Mycoinsecticides and mycoacaricides: a comprehensive list with worldwide coverage and international classification of formulation types. Biol Control. 2007; 43:237-256. | Article

10. Fernandes ÉKK, Keyser CA, Rangel DEN, Foster RN and Roberts DW. CTC médium: a novel dodine-free selective medium for isolating entomopathogenic fungi, especially Metarhizium acridium, from soil. Biol Control. 2010; 54:197- 205.

11. Foth HD. Fundamentals of Soil Science. John Wiley \& Sons, London. 1984.

12. Fraga ME, Braz DM, Rocha JF, Pereira MG and Figueiredo DV. Interação microrganismo, solo e flora como condutores de biodiversidade na Mata Atlântica. Acta Bot Bras. 2012, 26:857-865. | Article

13. Goettel MS and Inglis D. Fungi: Hyphomycetes. In: Lacey L. (Ed.) Manua of techniques in insect pathology. San Diego: Academic Press. 1997; 213-249.

14. Hibbett DS, Ohman A, Glotzer D, Nuhn M, Kirk P and Nilsson RH. Progress in molecular and morphological taxon discovery in Fungi and options for formal classification of environmental sequences. Fungal Biol Rev. 2011; 25:38-47. | Article

15. Hughes WO, Thomsen L, Eilenberg J and Boomsma JJ. Diversity of entomopathogenic fungi near leaf-cutting ant nests in a neotropical forest, with particular reference to Metarhizium anisopliae var. anisopliae. J Invertebr Pathol. 2004; 85:46-53. | Article | PubMed

16. Humber RA. Identification of entomopathogenic fungi, In: Lacey LA (Ed.), Manual of techniques in insect pathology, second ed. Academic Press, Inc., California, USA. 2012; 151-187.

17. Ignoffo CM. Effects of entomopathogens on vertebrates. Ann NY Acad Sci. 1973; 217:141-72. | Article I PubMed

18. Imoulan A, Alaoui A and El Meziane A. Occurrence and distribution of entomopathogenic fungi in Moroccan endemic forests of Argania spinosa. IOBC/wprs Bulletin. 2009; 45:316-319. | Article

19. Keller S, Zimmermann G: Mycopathogens of soil insects. In: Wilding N, Collins NM, Hammond, PM, Webber JF (eds) Insect-Fungus Interactions. Academic Press, London. 1989; 239-270.

20. Keller $L$ and Bidochka MJ. Habitat and temporal differences among soil microfungal assemblages in Ontario. Can J Botany. 1998; 76:1798-1805. | Article

21. Keller S, Kessler P and Schweizer C. Distribution of insect pathogenic soil fungi in Switzerland eith special reference to Beauveria brongniartii and Metarhizium anisopliae. Biocontrol. 2003; 48:307-319. | Article

22. Klingen I, Eilenberg $J$ and Meadow R. Effects of farming system, field margins and bait insect on the occurrence of insect pathogenic fungi in soils. Agr Ecosyst Environ. 2002; 91:191-198. | Article

23. Landa Z, Hornák P, Charvátová $H$ and Osborne LS. Distribution, Occurrence and Potential Use of Entomopathogenic Fungi in Arable Soils in Czech Republic. ISTRO-Conference, Brno, Session II. 2002; 195201.

24. Lingg AJ and Donaldson MD. Biotic and abiotic factors affecting stability of Beauveria bassiana conidia in soil. J Invertebr Pathol. 1981; 38:191200. | Article

25. Liu ZY, Milner R J, Mcrae CF and Lutton GG. The use of Dodine in selective media for the isolation of Metarhizium spp. From soil. $J$ Invertebr Pathol. 1993; 62:248-251. | Article

26. Luz C, Netto MC and Rocha LF. In vitro susceptibility to fungicides by invertebrate-pathogenic and saprobic fungi. Mycopathologia. 2007; 164:39-47. | Article | PubMed

27. Medo $\mathrm{J}$ and Cagan L. Factors affecting the occurrence of entomopathogenic fungi in soils of Slovakia as revealed using two methods. Biol Control. 2011; 59:200-208. | Article

28. Meyling NV and Eilenberg J. Ocurrence and distribution of soil borne entomopathogenic fungi within a single organic agroecosystem. Agr Ecosyst Environ. 2006; 113:336-341. | Article

29. Meyling NV and Eilenberg J. Ecology of the entomopathogenic fungi Beauveria bassiana and Metarhizium anisopliae in temperate agroecosystems: Potential for conservation biological control. Biol Control. 2007; 43:45-155. | Article

30. Meyling NV, Thorup KK and Eilenberg J. Below- and aboveground abundance and distribution of fungal entomopathogens in experimental conventional and organic cropping systems. Biol Control. 2011; 59:180-186. | Article

31. Pansu M and Gautheyrou J. Handbook of Soil Analysis, Mineralogical, Organic and Inorganic Methods, Springer Berlin Heidelberg. New York. 2006. | Article

32. Perez-Gonzalez VH, Guzman-Franco AW, Alatorre-Rosas R, HernandezLopez J, Hernandez-Lopez A, Carrillo-Benitez MG and Baverstock J. Specific diversity of the entomopathogenic fungi Beauveria and Metarhizium in Mexican agricultural soils. J Invertebr Pathol. 2014; 119:54-61. | Article | PubMed

33. Quesada-Moraga E, Navas-Cortes JA, Maranhao EA, Ortiz-Urquiza A and Santiago-Alvarez $\mathrm{C}$. Factors affecting the occurrence and distribution of entomopathogenic fungi in natural and cultivated soils. Mycol Res. 2007; 111:947-66. | Article | PubMed

34. Rocha LF, Inglis PW, Humber RA, Kipnis A and Luz C. Occurrence of Metarhizium spp. in Central Brazilian soils. J Basic Microbiol. 2013; 53:251-9. | Article | PubMed

35. Samson RA, Evans HC and Latgé JP. Atlas of entomopathogenic fungi. Springer, Berlin Heidelberg New York. 1988. I Article

36. Scheepmaker JWA and Butt TM. Natural and released inoculum levels 
of entomopathogenic fungal biocontrol agents in soil in relation to risk assessment and in accordance with EU regulations. Biocontrol Sci Techn. 2010; 20:503-552. | Article

37. Shimazu M, Sato $H$ and Maehara N. Density of the entomopathogenic fungus, Beauveria bassiana Vuillemin (Deuteromycotina: Hyphomycetes) in forest aie and soil. Appl Entomol Zool. 2002; 37:19-26. I Article

38. Steenberg T. Natural occurrence of Beauveria bassiana (Bals.) Vuill. with focus on infectivity to Sitona species and other insects in lucerne. Ph.D. thesis. Royal Veterinary and Agricultural University, Copenhagen, Denmark. 1995.

39. St Leger RJ and Wang C. Genetic engineering of fungal biocontrol agents to achieve greater efficacy against insect pests. Appl Microbiol Biotechnol. 2010; 85:901-7. | Article | PubMed

40. Storey GK, Mccoy CW, Stenzel K and Andersch W. Conidiation kinetics of the mycelial granules of Metarhizium anisopliae (BIO 1020) and its biological activity against different soil insects. Proc. and abstracts of Vth Intern. Colloquium on Invertebrate Pathology and Microbial Control. 1990; 320-325. | Article

41. Studdert JP, Kaya HK and Duniway JM. Effect of water potential, temperature, and clay-coating on survival of Beauveria bassiana conidia in a loam and peat soil. J Invertebr Pathol. 1990; 55:417-427. | Article

42. Sun B, Han-ying $Y$, Amanda J and Liu X. Insect-associated fungi in soils of field crops and orchards. Crop Prot. 2008; 27:1421-1426. | Article

43. Tkaczuk $C$ and Mietkiewski R. Occurrence of entomopathogenic fungi in different kinds of soil. Rocz. RoczNauk Roln, Ser E. 1996; 25:41-46.

44. Vanninen I, Husberg GB and Hokkanen HMT. Occurrence of entomopathogenic fungi and entomoparasitic nematodes in cultivated soils in Finland. Acta Entomol Fenn. 1989; 53:65-71.

45. Vanninen I. Distribution and occurrence of four entomopathogenic fungi in Finland: effect of geographical location, habitat type and soil type. Mycol Res. 1996; 100:93-101. | Article

46. Vanninen I. Distribution and occurrence of four entomopathogenic fungi in soil. Mycol Res. 1996; 100:93-101. | Article

47. Vega FE, Meyling N, Luangsa-Ard J and Blackwell M. Fungal Entomopathogens. In: Vega FE, Kaya HK (Eds), Insect Pathology, Second edition, Acadeic press, San Diego. 2012; 171-220.

48. Woodring JL and Kaya HK. Steinernematid and Heterorhabditid Nematodes: A handbook of Biology and Techniques. Arkansas Agricultural experiment station, Fayetteville, Arkansas. 1988.

49. Zimmermann $\mathrm{G}$. The Galleria bait method for detection of entomopathogenic fungi in soil. J Appl Entomol. 1986; 102:213-215. | Article

50. Zimmermann G. Review on safety of the entomopathogenic fungi Beauveria bassiana and Beauveria brongniartii. Biocontrol Sci Techn. 2007; 17:553-596. | Article

51. Zimmermann G. The entomopathogenic fungi Isaria farinose (formerly Paecilomyces farinosus) and the Isaria fumosorosea species complex (formerly Paecilomyces fumosoroseus): biology, ecology and use in biological control. Biocontrol Sci Techn. 2008; 18:865-901. | Article

\section{Citation:}

Esparza Mora MA, Costa Rouws JR and Fraga ME. Occurrence of entomopathogenic fungi in Atlantic forest soils. Microbiol Discov. 2016; 4:1.

http://dx.doi.org/10.7243/2052-6180-4-1 